\title{
What did we learn in 65 years? How often and why should an echocardiography follow-up be undertaken?
}

\section{(D) Mario Ivanuša ${ }^{1,2 *}$ DDomagoj Ivanuša ${ }^{3}$, (1) Vlatka Rešković Lukšić ${ }^{4}$ \\ DDadranka Šeparović Hanževački ${ }^{4}$ \\ 'Institute for Cardiovascular Prevention and Rehabilitation, Zagreb, Croatia \\ ${ }^{2}$ Univesity of Rijeka, Faculty of Medicine, Rijeka, Croatia \\ ${ }^{3}$ University of Luxembourg, Faculty of Law, Economics and Finance, Luxembourg, Grand Duchy of Luxembourg ${ }^{4}$ University of Zagreb School of Medicine, University Hospital Centre Zagreb, Zagreb, Croatia}

\section{RECEIVED:}

February 28, 2019

ACCEPTED:

March 24, 2019

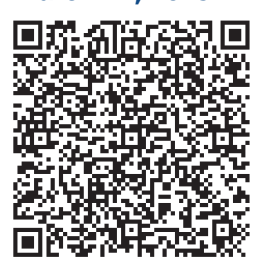

\author{
KEYWORDS: echocardiography, follow-up, guidelines, quality. \\ CITATION: Cardiol Croat. 2019;14(3-4):82-3. | https://doi.org/10.15836/ccar2019.82
}

*ADDRESS FOR CORRESPONDENCE: Mario Ivanuša, Poliklinika za prevenciju kardiovaskularnih bolesti i rehabilitaciju, Draškovićeva 13, HR-10000 Zagreb, Croatia. / Phone: +385-1-4612-290; Fax: +385-1-4612-343 / E-mail: mivanusa@gmail.com ORCID: Mario Ivanuša, https://orcid.org/0000-0002-6426-6831 • Domagoj Ivanuša, https://orcid.org/0000-0002-3137-5775 Vlatka Rešković Lukšić, http://orcid.org/0000-0002-4721-3236 • Jadranka Šeparović Hanževački, https://orcid.org/0000-0002-3437-6407

\section{||||||||||||||||||||||||||||||||||||||||||||||||||||||||||||||||||||||||||||||||||||||||||||||||||||||||||||||||||||||||||||||||||}

Comparably to almost every scientific discipline or field of study, medicine has also drastically revolutionized its methods and diagnostics throughout the last centuries. One of the most important milestones in the field of cardiology was the development of cardiological diagnostic test and procedures. The conceptualization of transthoracic echocardiography (TTE) was brought forward already 65 years ago when Edler and Hertz noted down movements of the heart walls "in the normal and in the diseased heart" by using 2,5MHz transducer in vivo connected to the cathode-ray-tube screen. ${ }^{1}$ The penetration of TTE method has significantly changed the course of cardiology in the XX and XXI century, due to the vast amount of data gathered through non-invasive and non-harmful applicability used for creating a diagnostic and therapeutic impact. Nowadays, TTE and its use have been framed through a standard protocol$^{2}$, indications ${ }^{3}$ and guidelines ${ }^{4}$ published on a constant basis by different professional societies (Table 1). In the upcoming years, alongside the increase of the volume, the development of TTE will be further stimulated by: a) growing demand for handheld or portable echocardiography devices, b) increased use of automated function imaging and c) emergence of 5D imaging technology.

Current research shows that there is still room for improvement regarding the optimal use of TTE when it comes to patients with acute myocardial infarction, heart failure, arrhythmias, stroke, sepsis

TABLE 1. State-of-the-art overview of standards/clinical practice guidelines created by professional societies for transthoracic echocardiography.

- EACVI Compendium - comprehensive compilation of all its recommendations, position papers and consensus statements published in the EHJ-CVI journal. EACVI E-Store. https://www.escardio.org/Sub-specialty-communities/European-Association-of-Cardiovascular-Imaging-(EACVI)/Education/E-Store

- Mitchell C, Rahko PS, Blauwet LA, Canaday B, Finstuen JA, Foster MC, et al. Guidelines for Performing a Comprehensive Transthoracic Echocardiographic Examination in Adults: Recommendations from the American Society of Echocardiography. J Am Soc Echocardiogr. 2019 Jan;32(1):1-64. https://doi.org/10.1016/j.echo.2018.06.004

- Galderisi M, Cosyns B, Edvardsen T, Cardim N, Delgado V, Di Salvo G, et al; 2016-2018 EACVI Scientific Documents Committee; 2016-2018 EACVI Scientific Documents Committee. Standardization of adult transthoracic echocardiography reporting in agreement with recent chamber quantification, diastolic function, and heart valve disease recommendations: an expert consensus document of the European Association of Cardiovascular Imaging. Eur Heart J Cardiovasc Imaging. 2017 Dec 1;18(12):1301-1310. https://doi.org/10.1093/ehjci/jex244

- Wharton G, Steeds R, Allen J, Phillips H, Jones R, Kanagala P, et al. A minimum dataset for a standard adult transthoracic echocardiogram: a guideline protocol from the British Society of Echocardiography. Echo Res Pract. 2015 Mar 1;2(1):G9-G24. https://doi.org/10.1530/ERP-14-0079

- Jeanrenaud X, Seiler C, Attenhofer Jost C, Kaufmann B, Gruner C et al; Board of the Working Group Echocardiography and Cardiac Imaging of the Swiss Society of Cardiology. What is a standard transthoracic echocardiogram performed by a cardiologist? MÉDECINE CARDIOVASCULAIRE. 2015;18(4):146-151. http://www.swisscardio.ch/ DOCS_PUBLIC/Empfehlungen_Richtlinien/What_is_a_standard_transthoracic_echo_2015.pdf

- Lancellotti P, Płońska-Gościniak E, Garbi M, Bucciarelli-ducci C, Cosyns B, Cardim N, et al. Cardiovascular imaging practice in Europe: a report from the European Association of Cardiovascular Imaging. Eur Heart J Cardiovasc Imaging. 2015 Jul;16(7):697-702. https://doi.org/10.1093/ehjci/jev116

- Popescu BA, Stefanidis A, Nihoyannopoulos P, Fox KF, Ray S, Cardim N, et al. Updated standards and processes for accreditation of echocardiographic laboratories from The European Association of Cardiovascular Imaging: an executive summary. Eur Heart J Cardiovasc Imaging. 2014 Nov;15(11):1188-93. https://doi.org/10.1093/ehjci/jeu057 
or in critically ill patients. This could be partially regarded to the fact that 35-50\% of patients will repeat their TTE within one to three years from the first examination but this will yield any significant change in the outcome of patients only in less than a third of cases. ${ }^{5}$ Even though the TTE is a low-risk, the consequences of over-use could be false positive tests, downstream utilization of resources, and an increase in overall costs. There are a few methods of addressing over-testing: a) clinical practice guidelines (available in both hard copy form and on the Internet; Table 1), b) appropriate use criteria ${ }^{6-8}$ (the nomenclature for appropriate use categorization: appropriate, may be appropriate, and rarely appropriate procedures; Table 2), c) changes in financial incentives, d) education and training e) national campaigns and public awareness, f) change in assessment of the value of diagnostic testing, etc. Recently in order to improve all aspects of the overall health care service, British Society of Echocardiography has published The Echocardiography Quality Framework ${ }^{9}$. Alongside, the quality of echocardiography these methods also include reproducibility and consistency, education and training, and customer feedback.

\section{TABLE 2. An overview of top articles on the topic of the appropriate use of the criteria for echocardiography.}

- Doherty JU, Kort S, Mehran R, Schoenhagen P, Soman P, Dehmer GJ, et al. ACC/AATS/AHA/ASE/ASNC/HRS/SCAI/SCCT/SCMR/STS 2019 Appropriate Use Criteria for Multimodality Imaging in the Assessment of Cardiac Structure and Function in Nonvalvular Heart Disease. J Am Coll Cardiol. 2019 Feb 5;73(4):488-516. https://doi.org/10.1016/j.jacc.2018.10.038

- Doherty JU, Kort S, Mehran R, Schoenhagen P, Soman P. ACC/AATS/AHA/ASE/ASNC/HRS/SCAI/SCCT/SCMR/STS 2017 Appropriate Use Criteria for Multimodality Imaging in Valvular Heart Disease. J Am Coll Cardiol. 2017 Sep 26;70(13):1647-1672. https://doi.org/10.1016/j.jacc.2017.07.732

- Fonseca R, Jose K, Marwick TH. Understanding decision-making in cardiac imaging: determinants of appropriate use. Eur Heart J Cardiovasc Imaging. 2018 Mar 1;19(3):262-268. https://doi.org/10.1093/ehjci/jex257

- Steeds RP, Garbi M, Cardim N, Kasprzak JD, Sade E, Nihoyannopoulos P, et al; 2014-2016 EACVI Scientific Documents Committee; 2014-2016 EACVI Scientific Documents Committee. EACVI appropriateness criteria for the use of transthoracic echocardiography in adults: a report of literature and current practice review. Eur Heart J Cardiovasc Imaging. 2017 Nov 1;18(11):1191-1204. https://doi.org/10.1093/ehjci/jew333

- Chambers JB, Garbi M, Nieman K, Myerson S, Pierard LA, Habib G, et al. Appropriateness criteria for the use of cardiovascular imaging in heart valve disease in adults: a European Association of Cardiovascular Imaging report of literature review and current practice. Eur Heart J Cardiovasc Imaging. 2017 May 1;18(5):489-498. https://doi.org/10.1093/ehjci/jew309

- Douglas PS, Garcia MJ, Haines DE, Lai WW, Manning WJ, Patel AR, et al. ACCF/ASE/AHA/ASNC/HFSA/HRS/SCAI/SCCM/SCCT/SCMR 2011 Appropriate Use Criteria for Echocardiography. J Am Soc Echocardiogr. 2011 Mar;24(3):229-67. https://doi.org/10.1016/j.echo.2010.12.008

In March 2019, Nucleus of the Working Group on Echocardiography and Cardiac Imaging Modalities of the Croatian Cardiac Society has investigated the frequency of the echocardiography follow-ups in different clinical case scenarios. The anonymous online questionnaire was distributed by e-mail to subscribers of the kardio.hr newsletter, who were voluntarily requested to answer on 10 questions. The questionnaire was comprised of two parts - routine procedures in the echocardiography laboratory (first five questions) and the perceived frequency of the need for repeating TTE follow-ups (second five questions). The routine procedures have been analyzed with the length of the echocardiography experience, order for procedures, indications for the first and the control examination and the frequency of follow-ups as explanatory variables. Moreover, the perceived frequency of the need for repeating the TTE check-ups has been investigated through several possible clinical scenarios such as patients with arterial hypertension, mitral valve prolapse, after an acute myocardial infarction as well as patients with the aortic stenosis or implanted aortic valve.

LITERATURE IIIIIIIIIIIIIIIIIIIIIIIIIIIIIIIIIIIIIIIIIIIIIIIIIIIIIIIIIIIIIIIIIIIIIIIIIIIIIIIIIIIIIIIIIIIIIIIIIIIIIIIIIIIIIIIIIIIIIIIIIIIIIIIIIIIIIIIIIII

1. Edler I, Hertz CH. The use of ultrasonic reflectoscope for the continuous recording of the movements of heart walls. 1954. Clin Physiol Funct Imaging. 2004 May:24(3):118-36. https://doi.org/10.1111/j.1475-097X.2004.00539.x

2. Galderisi M, Cosyns B, Edvardsen T, Cardim N, Delgado V, Di Salvo G, et al; 2016-2018 EACVI Scientific Documents Committee; 2016-2018 EACVI Scientific Documents Committee. Standardization of adult transthoracic echocardiography reporting in agreement with recent chamber quantification, diastolic function, and heart valve disease recommendations: an expert consensus document of the European Association of Cardiovascular Imaging. Eur Heart J Cardiovasc Imaging. 2017 Dec 1;18(12):1301-1310. https://doi.org/10.1093/ehjii/jex244

3. British Society of Echocardiography. Indications for echocardiography. Available from: https://www.bsecho.org/indications-for-echocardiography (March 20, 2019).

4. Mitchell C, Rahko PS, Blauwet LA, Canaday B, Finstuen JA, Foster MC, et al. Guidelines for Performing a Comprehensive Transthoracic Echocardiographic Examination in Adults: Recommendations from the American Society of Echocardiography. J Am Soc Echocardiogr. 2019 Jan;32(1):1-64. https://doi.org/10.1016/j.echo.2018.06.004

5. Welch HG, Hayes KJ, Frost C. Repeat testing among Medicare beneficiaries. Arch Intern Med. 2012 Dec 10;172(22):1745-51. https://doi.org/10.1001/2013.jamainternmed.727

6. Delgado V, Cardim N, Cosyns B, Donal E, Flachskampf F, Galderisi M, et al. Criteria for recommendation, expert consensus, and appropriateness criteria papers: update from the European Association of Cardiovascular Imaging Scientific Documents Committee. Eur Heart J Cardiovasc Imaging. 2018 Aug 1;19(8):835-837. https://doi.org/10.1093/ehjici/jey079

7. Chambers JB, Garbi M, Nieman K, Myerson S, Pierard LA, Habib G, et al. Appropriateness criteria for the use of cardiovascular imaging in heart valve disease in adults: a European Association of Cardiovascular Imaging report of literature review and current practice. Eur Heart J Cardiovasc Imaging. 2017 May 1;18(5):489-498. https://doi.org/10.1093/ehjii/jew309

8. Garbi M, Edvardsen T, Bax J, Petersen SE, McDonagh T, Filippatos G, et al. EACVI appropriateness criteria for the use of cardiovascular imaging in heart failure derived from European National Imaging Societies voting. Eur Heart J Cardiovasc Imaging. 2016 Jul;17(7):711-21. https://doi.org/10.1093/ehjci/jew081

9. Masani N. The Echocardiography Quality Framework: a comprehensive, patient-centered approach to quality assurance and continuous service improvement. Echo Res Pract. 2018 Dec; 5(4): G35-G41. https://dx.doi.org/10.1530\%2FERP-18-0052 